\title{
Utilization of Dental Service and Quality of Life in Preschool Children
}

\author{
${ }^{1}$ Nur Sisman, ${ }^{2}$ Nilufer Bora, ${ }^{3}$ Ramazan O Catar, ${ }^{4}$ Umit Karacayli, ${ }^{5}$ Hale Cimilli, ${ }^{6}$ Leyla Koksal \\ ${ }^{7}$ Inci Oktay, ${ }^{8}$ Gonca Mumcu
}

\begin{abstract}
Aim: The aim of the study was to evaluate the relationship between dental service utilization and oral health-related quality of life status in preschool children.
\end{abstract}

Materials and methods: In this cross-sectional study, 165 five-year-old preschool children (F/M: 77/88) were included. Data were collected by clinical examinations, a questionnaire regarding oral health-related factors, and early childhood oral health impact scale (ECOHIS) for oral health-related quality of life.

Results: In emergency visits, the ratios of having dental pain, dental sensitivity, tooth decay, tooth loss were higher than the others $(p<0.05)$. Moreover, ECOHIS-Total, ECOHIS-Child, and ECOHIS-Family scores were higher in children with poor oral health status compared with good ones $(p<0.05)$.

Conclusion: Early childhood oral health impact scale score related with oral health status could be used to evaluate priority for emergencies in this age group.

Keywords: Dental service utilization, Preschool children, Quality of life.

How to cite this article: Sisman N, Bora N, Catar RO, Karacayli U, Cimilli H, Koksal L, Oktay I, Mumcu G. Utilization of Dental Service and Quality of Life in Preschool Children. Int J Experiment Dent Sci 2016;5(1):16-22.

Source of support: Nil

Conflict of interest: None

\section{INTRODUCTION}

According to the World Health Organization (WHO), poor oral healthcare is a serious burden for all countries

\footnotetext{
${ }^{1,3,6}$ Assistant Professor, ${ }^{2}$ Private Practitioner, ${ }^{4}$ Associate Professor, ${ }^{5,7,8}$ Professor

$1,3,6,8$ Department of Health Management, Faculty of Health Sciences, Marmara University, Istanbul, Turkey

${ }^{2}$ Department of Public Oral Health, Istanbul, Turkey

${ }^{4}$ Department of Oral and Maxillofacial Surgery, Gulhane Military Medical Academy, Ankara, Turkey

${ }^{5}$ Department of Endodontics, Faculty of Dentistry, Marmara University, Istanbul, Turkey

${ }^{7}$ Department of Oral Public Health, Faculty of Dentistry Yeditepe University, Istanbul, Turkey

Corresponding Author: Nur Sisman, Assistant Professor Department of Health Policy, Marmara University, Istanbul Turkey Phone: 009002163999371, e-mail: sisman.nur@gmail.com
}

worldwide. Oral health surveys are carried out to analyze and interpret the current conditions for policy-makers and decision-makers. ${ }^{1-3}$ Utilization of dental service is an essential component of oral health and health care planning in the frame of health policy. It could be different according to perceived dental health, health beliefs, attitudes toward dental problems, financial status of the individuals, ${ }^{4}$ and organization of dental services in the country. ${ }^{5,6}$ In addition to all, parents' profile and parental perceptions ${ }^{7}$ relating to children's oral health status are also prominent factors in the oral health status of children.

Oral health needs are determined by families and health professionals in children. Therefore, parents have important roles in oral health status and utilization of dental service in children. ${ }^{6,8-10}$ Education level, ${ }_{11}^{11}$ opinions about oral health, and income level of parents are key factors for oral health of children. ${ }^{12}$ Moreover, oral health-related quality of life status could also be affected by these conditions significantly. ${ }^{13}$ Objective clinical parameters, such as dental caries and tooth loss are thought as critical factors in the organization of dental services, whereas impact of dental problems on quality of life is underestimated. Therefore, the aim of the study was to evaluate the relationship among oral health, utilization pattern of dental service, and quality of life status in preschool children.

\section{MATERIALS AND METHODS}

In this cross-sectional study, 165 five-year-old preschool children (F/M:77/88) were included. Data were collected by clinical examinations and quality of life questionnaire regarding early childhood oral health impact scale (ECOHIS) that is a validated measurement and specific questionnaire for oral health-related quality of life status in children. ${ }^{14}$ After parents' approval was received, questionnaires and dental history of children were filled by parents.

Early childhood oral health impact scale questionnaire was translated into Turkish in accordance with crosscultural adaptation guidelines to produce its Turkish version. Forward and backward translation of ECOHIS was performed by a small group of bilingual (English and Turkish) translators, including two professional translators and two dentists. Early childhood oral health impact scale consists of two main parts regarding child and family. 
The questionnaire form is scored according to five-point Likert scale. Increase in ECOHIS score refers to poor oral health in children.

Utilization of dental service was evaluated as emergency and regular dental visits. Then, associations among ECOHIS scores and oral health were examined in order to test the construct validity. Criterion validity was evaluated by self-reported oral health status with face figures (excellent/very good, good, and poor/fair). Reliability was evaluated in two ways: Internal reliability (Cronbach's alpha) and external reliability; external reliability was assessed by test-retest. They were found to be ECOHIS-Total 0.8331, ECOHIS-Child 0.8183, and ECOHIS-Family 0.7477. Test-retest analysis was carried out in randomly selected 17 children after a period of 1 week.

The exclusion criteria for the study were the presence of systemic diseases, psychiatric disorders, and oral mucosal disorders. The study was approved by the Marmara University Local Ethics Committee and informed consent was taken by parents.

\section{Statistical Analysis}

Data were analyzed by using SPSS and PSPP open source statistical analysis software. Independent t-test was used in comparisons of groups. The nonparametric test, Mann-
Whitney U-test, was used when the distributions of data were non-normal and few subjects were included in the analyses. The relationship between clinical variables and scores of questionnaire was evaluated by Pearson correlation test. The $p$ value equal to or less than 0.05 was accepted as significant.

\section{RESULTS}

In this cross-sectional study, 165 healthy children who were 5 years old (F/M: 77/88) were included. The mean height and weight of the children were $113.5 \pm 4.54 \mathrm{~cm}$ and $21.5 \pm 4.78 \mathrm{~kg}$ respectively. Education years were $13.05 \pm 2.6$ in mothers and $13 \pm 2.23$ in fathers in the group.

The first toothbrushing was started almost at the age of 3 years (33.09 \pm 14.53 months) and the frequency of brushing teeth was at least once a day in these children. Starting to brush teeth was weakly correlated with education years of mother $(r-0.33, \mathrm{p}=0.002)$.

The ratios of having dental pain, dental sensitivity, tooth decay, loss of deciduous teeth, halitosis, and broken teeth were higher in patients with emergency dental examination than the others ( $\mathrm{p}=0.001,0.021,0.009,0.014$, 0.025 , and 0.041 respectively) (Table 1 ).

Early childhood oral health impact scale-Total and ECOHIS-Child scores were significantly higher in children

Table 1: Symptoms in emergency dental visits in the study group

\begin{tabular}{|c|c|c|c|c|c|c|}
\hline & \multicolumn{2}{|c|}{ Emergency dental visit } & \multicolumn{2}{|c|}{ Regular dental visit } & \multicolumn{2}{|c|}{ Total } \\
\hline & $n$ & $\%$ & $n$ & $\%$ & $n$ & $\%$ \\
\hline \multicolumn{7}{|c|}{ Dental pain } \\
\hline Present & 31 & 81.6 & 7 & 18.4 & 38 & 100.0 \\
\hline Absent & 60 & 51.7 & 56 & 48.3 & 116 & 100.0 \\
\hline$p$-value ${ }^{b}$ & \multicolumn{6}{|c|}{0.001} \\
\hline \multicolumn{7}{|c|}{ Dental sensitivity } \\
\hline Present & 28 & 75.7 & 9 & 24.3 & 37 & 100.0 \\
\hline Absent & 62 & 53.4 & 54 & 46.6 & 116 & 100.0 \\
\hline$p$-value ${ }^{b}$ & \multicolumn{6}{|c|}{0.021} \\
\hline \multicolumn{7}{|c|}{ Tooth decay } \\
\hline Present & 40 & 74.1 & 14 & 25.9 & 54 & 100.0 \\
\hline Absent & 51 & 51.5 & 48 & 48.5 & 99 & 100.0 \\
\hline$p$-value ${ }^{b}$ & \multicolumn{6}{|c|}{0.009} \\
\hline \multicolumn{7}{|c|}{ Loss of deciduous teeth } \\
\hline Present & 17 & 85.0 & 3 & 15.0 & 20 & 100.0 \\
\hline Absent & 73 & 55.3 & 59 & 44.7 & 132 & 100.0 \\
\hline$p$-value ${ }^{b}$ & \multicolumn{6}{|c|}{0.014} \\
\hline \multicolumn{7}{|l|}{ Halitosis } \\
\hline Present & 9 & 90.0 & 1 & 10.0 & 10 & 100.0 \\
\hline Absent & 82 & 56.9 & 62 & 43.1 & 144 & 100.0 \\
\hline$p$-value ${ }^{c}$ & \multicolumn{6}{|c|}{0.025} \\
\hline \multicolumn{7}{|c|}{ Mobility in deciduous teeth } \\
\hline Present & 4 & 80.0 & 1 & 20.0 & 5 & 100.0 \\
\hline Absent & 83 & 57.2 & 62 & 42.8 & 145 & 100.0 \\
\hline$p$-value ${ }^{a}$ & \multicolumn{6}{|c|}{0.311} \\
\hline
\end{tabular}




\begin{tabular}{|c|c|c|c|c|c|c|}
\hline & \multicolumn{2}{|c|}{ Emergency dental visit } & \multicolumn{2}{|c|}{ Regular dental visit } & \multicolumn{2}{|c|}{ Total } \\
\hline & $n$ & $\%$ & $n$ & $\%$ & $n$ & $\%$ \\
\hline \multicolumn{7}{|c|}{ Broken tooth } \\
\hline Present & 6 & 100.0 & 0 & 0.0 & 6 & 100.0 \\
\hline Absent & 93 & 58.5 & 66 & 41.5 & 159 & 100.0 \\
\hline$p$-value ${ }^{b}$ & \multicolumn{6}{|c|}{0.041} \\
\hline \multicolumn{7}{|c|}{ Anterior tooth loss } \\
\hline Present & 6 & 85.7 & 1 & 14.3 & 7 & 100.0 \\
\hline Absent & 93 & 58.9 & 65 & 41.1 & 158 & 100.0 \\
\hline$p$-value ${ }^{b}$ & \multicolumn{6}{|c|}{0.240} \\
\hline
\end{tabular}

${ }^{a}$ Chi-square test; ${ }^{b}$ Fisher exact test; ${ }^{c}$ Yates (likelihood ratio $p$ ) were used in the analysis

having dental pain, dental sensitivity, tooth decay, loss of deciduous, orthodontic problem, halitosis, and anterior tooth loss compared with others $(\mathrm{p}<0.05)$. In addition to all of these, children with broken teeth had higher ECOHIS-Child score $(p=0.023)$. Increase in ECOHIS-Total, ECOHIS-Child, and ECOHIS-Family scores was seen in children with halitosis than those without halitosis ( $p=0.001,0.01$ and 0.024 respectively). Early Childhood Oral Health Impact Scale-Family score was higher in children with tooth mobility than those without it $(\mathrm{p}=0.001)$ (Table 2). Moreover, ECOHIS-Total score was strongly correlated with ECOHIS-Child score (Graph 1) and ECOHISFamily score $(\mathrm{r}=0.93, \mathrm{p}=0.000 ; \mathrm{r}=0.71, \mathrm{p}=0.000)$.
When scores were compared with self-reported oral health status, scores of ECOHIS-Total, ECOHIS-Child, and ECOHIS-Family were higher in poor oral health status compared with good ones $(p<0.05)$ (Table 3$)$. The correlations between each individual item and the ECOHIS-Total score were between 0.49 and 0.70 in these children. No correlation was observed to be negative in these instruments. No significant difference was seen in test-retest results (ECOHIS-Total $19.43 \pm 6.09$, ECOHIS-Child $12.94 \pm 4.80$, and ECOHIS-Family $6.37 \pm$ 2.87 vs ECOHIS-Total $19.37 \pm 5.23$, ECOHIS-Child 12.37 \pm 3.53 , and ECOHIS-Family $7.00 \pm 3.26$ respectively) $(\mathrm{p}>0.05)$.

Table 2: ECOHIS scores according to dental health problems in the group

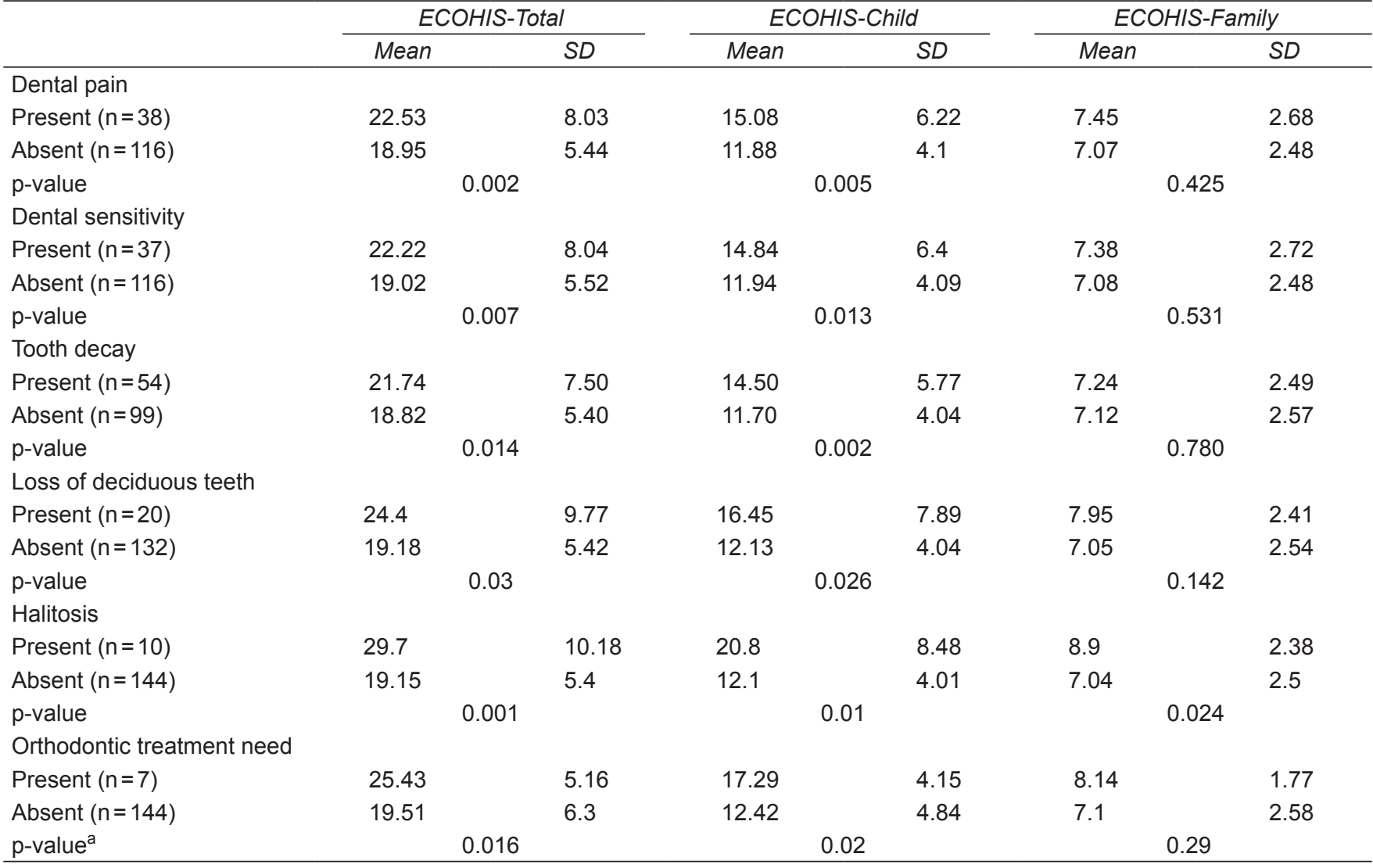


Contd...

\begin{tabular}{|c|c|c|c|c|c|c|}
\hline & \multicolumn{2}{|c|}{ ECOHIS-Total } & \multicolumn{2}{|c|}{ ECOHIS-Child } & \multicolumn{2}{|c|}{ ECOHIS-Family } \\
\hline & Mean & $S D$ & Mean & $S D$ & Mean & $S D$ \\
\hline \multicolumn{7}{|c|}{ Mobility in deciduous teeth } \\
\hline Present $(n=5)$ & 35 & 14.16 & 24.2 & 13.38 & 10.8 & 1.92 \\
\hline Absent $(n=145)$ & 19.17 & 5.19 & 12.16 & 3.88 & 7.01 & 2.48 \\
\hline$p$-value ${ }^{a}$ & \multicolumn{2}{|c|}{0.067} & \multicolumn{2}{|c|}{0.095} & \multicolumn{2}{|c|}{0.001} \\
\hline \multicolumn{7}{|l|}{ Broken tooth } \\
\hline Present $(n=6)$ & 27.5 & 15.05 & 19.33 & 12.07 & 8.16 & 2.99 \\
\hline Absent $(n=159)$ & 19.58 & 5.62 & 12.42 & 4.21 & 7.17 & 2.51 \\
\hline$p$-value $e^{a}$ & \multicolumn{2}{|c|}{0.094} & \multicolumn{2}{|c|}{0.023} & \multicolumn{2}{|c|}{0.520} \\
\hline \multicolumn{7}{|l|}{ Anterior tooth loss } \\
\hline Present $(n=7)$ & 28.0 & 13.98 & 20.28 & 10.62 & 7.71 & 3.54 \\
\hline Absent $(n=158)$ & 19.52 & 5.55 & 12.33 & 4.15 & 7.18 & 2.48 \\
\hline$p$-value ${ }^{a}$ & \multicolumn{2}{|c|}{0.040} & \multicolumn{2}{|c|}{0.003} & \multicolumn{2}{|c|}{0.844} \\
\hline
\end{tabular}

${ }^{a}$ Mann-Whitney U-test was used in the analysis; SD: Standard deviation; ECOHIS: Early childhood oral health impact scale

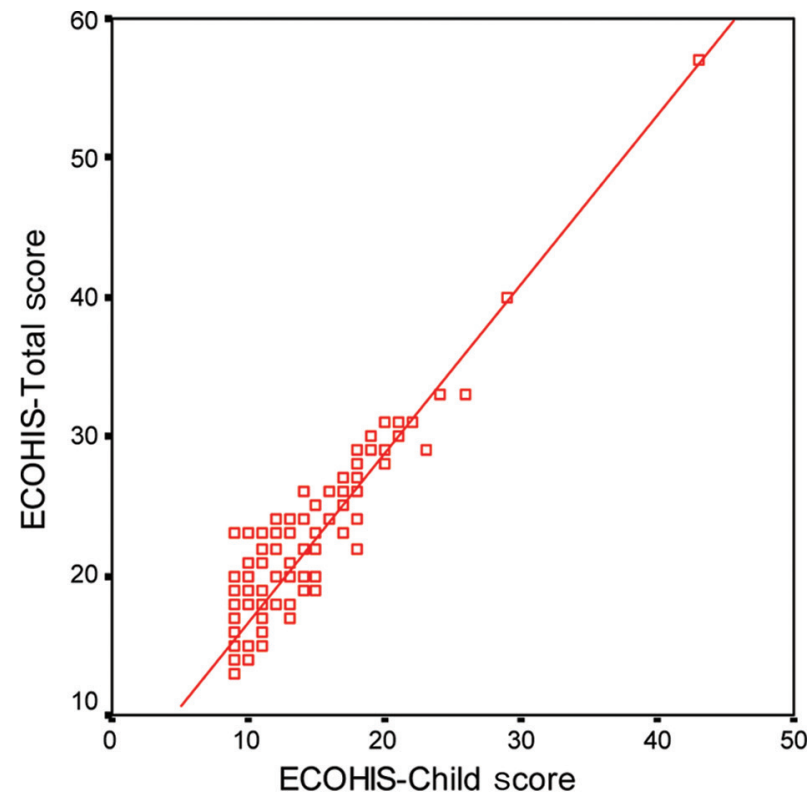

Graph 1: Relationship between ECOHIS-Total and ECOHIS-Child scores in children's oral health status $(n=165)$. (ECOHIS: Early childhood oral health impact scale)

Table 3: ECOHIS scores according to self-reported oral health status in the group

\begin{tabular}{|c|c|c|c|c|c|c|}
\hline \multirow{2}{*}{$\begin{array}{l}\text { Self-reported } \\
\text { oral health } \\
\text { status }\end{array}$} & \multicolumn{2}{|c|}{ ECOHIS-Total } & \multicolumn{2}{|c|}{ ECOHIS-Child } & \multicolumn{2}{|c|}{ ECOHIS-Family } \\
\hline & Mean & $S D$ & Mean & $S D$ & Mean & $S D$ \\
\hline $\begin{array}{l}\text { Fair/poor } \\
(n=14)\end{array}$ & 27.42 & 9.78 & 18.35 & 8.12 & 9.07 & 2.55 \\
\hline Good $(n=32)$ & 20.12 & 5.05 & 13.46 & 4.09 & 6.65 & 2.08 \\
\hline $\begin{array}{l}\text { Excellent/very } \\
\text { good }(n=107)\end{array}$ & 18.67 & 5.40 & 11.63 & 3.96 & 7.03 & 2.55 \\
\hline$p$-value* & \multicolumn{2}{|c|}{$0.000^{* *}$} & \multicolumn{2}{|c|}{$0.000^{* * *}$} & \multicolumn{2}{|c|}{$0.008^{* * * *}$} \\
\hline
\end{tabular}

*ANOVA was used in the analysis; ${ }^{* *}$ Fair/poor-Good $p=0.000$; Good-Excellent/very good $p=0.436$; Fair/poor-Excellent/very good $p=0.000 ;{ }^{* * *}$ Fair/poor-Good $p=0.003$; Good-Excellent/very good $p=0.111$; Fair/poor-Excellent/very good $p=0.000 ;{ }^{* * * *}$ Fair/ poor-Good $p=0.007$; Good-Excellent/very good $p=0.723$; Fair/ poor-Excellent/very good $p=0.012$; SD: Standard deviation; ECOHIS: Early Childhood Oral Health Impact Scale

\section{DISCUSSION}

In the present study, utilization of dental service pattern, oral health status, and oral health-related quality of life status was assessed in preschool children. Emergency dental visits were mainly seen in symptomatic conditions such as presence of dental pain, dental sensitivity, tooth decay, deciduous tooth loss, halitosis, orthodontic treatment need, and broken teeth in the present study. As it is predicted, increase in regular dental visits is critical condition for good oral health since emergency dental visits are very complicated in symptomatic patients. ${ }^{15}$ Therefore, regular dental checkups are critical points for oral health. The result was in accordance with results of our previous study, which suggested that utilization of oral health services is related to emergency conditions in our country. ${ }^{5}$

In the present study, oral health-related quality of life was evaluated by ECOHIS questionnaire including child and family parts. Early childhood oral health impact scale has been validated as a tool for assessing oral healthcare in children in different countries, such as Brazil ${ }_{,}^{16}$ China,${ }^{17}$ France, ${ }_{18}^{18}$ Persia, ${ }_{1}^{19}$ Bosnia-Herzegovina, ${ }^{20}$ USA, ${ }^{14}$ Canada, ${ }^{21}$ and Saudi Arabia. ${ }^{22}$ In the present study, ECOHIS-Total score was found to be more strongly correlated with ECOHIS-Child score than ECOHISFamily score. This result could be predicted since these domains are correlated parts of quality of life status reflecting patient perspective.

Early childhood oral health impact scale-total and ECOHIS-Child scores were found to be related to symptomatic dental conditions regarding pain, sensitivity, tooth decay, loss of teeth, and halitosis in the present study. Similarly, poor ECOHIS scores were observed in children with dental caries compared with those without. ${ }^{16,23,24}$ Especially, dental pain and sensitivity influence children's oral health negatively. ${ }^{25,26}$ 
Therefore, our results are in accordance with those of previous studies.

Poor oral quality of life status was seen in patients with orthodontic treatment need and anterior tooth loss affecting aesthetic concerns and functional status. Children without caries do not avoid showing teeth while smiling. They concluded that poor oral health such as having caries ${ }^{16}$ affect children's smiling attitudes. ${ }^{27}$ Orthodontic treatment need may commonly cause aesthetic concerns ${ }^{28}$ and may affect the children psychologically; children's perceived oral health differs in case of orthodontic treatment need because of physical appearance.

Dental health care status is needed to be improved in Turkey. In order to avoid poor oral health status in children, parental dental knowledge and habits should be promoted by national oral health programs. ${ }^{29,30}$ The implementation of oral health policies and oral health promotion among 5-6 year age group is essential to reduce the high prevalence of dental caries. ${ }^{16}$ It was interesting that increases in ECOHIS-Family score were seen in children with halitosis and tooth mobility. This result may be based on children's and their parents' perceived oral health. This situation may also cause concern in parents about children's oral health. Besides, halitosis could be caused by different aetiological factors besides poor oral health. If parents know the eruption time of teeth, they can easily understand the condition of tooth mobility. Therefore, irregular check-up and lack of information about oral health status could affect opinion of parents negatively.

In the present study, a weak correlation was seen between education level of mothers and the age at which brushing of teeth was started. Mothers could better understand their children's oral health compared with fathers. Also, cultural background of countries could affect the role of mother. Mothers have a prominent role in children's life. ${ }^{22}$ In our previous study, it was found that mother's habit of toothbrushing affected children's habits. ${ }^{6}$ As a result, mothers have a critical role in improving their children's oral health and quality of life status directly.

Self-reported oral health status was found to be as important a factor as criterion validity to understand oral health-related quality of status in the present study. When scores were compared with self-reported oral health status, scores of ECOHIS-Total, ECOHIS-Child, and ECOHIS-Family were found to be higher in poor oral health status compared with good ones $(p<0.05)$. This result might be used to get information both individually and strategies of oral healthcare planning. ${ }^{31}$ Especially, WHO suggests self-assessed oral health surveys to determine appropriate strategies in oral health promotion. ${ }^{1}$ Moreover, self-reported oral health status has been found to be related to quality of life status and possible treatment needs. ${ }^{18,32-34}$

Early childhood oral health impact scale could be used to evaluate treatment needs in the dental health care system. The results of the instrument might be part of the national health policy implications and dental health care service planning. ${ }^{1,35}$ Moreover, WHO suggested establishing a national oral health information system to organize and assess national oral health programs. ${ }^{1}$ Early preventive dental visit for preschool children affects subsequent preventive dental service utilization. Costs of untreated dental diseases could be lessened by early preventive dental visits. ${ }^{36}$ Schools could be part of health promotion applications. ${ }^{37,38}$ Oral health education for preschool could be organized with a multidisciplinary approach. In this frame, data regarding oral quality of life as the outcome measure could be recorded in the health information system for planning of preventive applications $^{39}$ and organizing oral health campaigns. ${ }^{40}$ Poor oral health causes increase in the utilization of emergency dental services. Increases in community health awareness and utilization of preventive healthcare service will decrease the demand for emergency dental services. Therefore, focusing on preventive health care services in oral health is essential for planning and organizing dental health care services. Moreover, WHO recommends oral health promotion strategies in national health programs, ${ }^{2,41}$ and global trends in delivery of health care service, such as mobile and portable dental services ${ }^{37}$ could be considered to improve oral health awareness and utilization of dental services.

\section{CONCLUSION}

In the frame of patients' perspective, patient-derived questionnaires give important information for the evaluation of the organizational pattern. Early childhood oral health impact scale questionnaire was found to be related to oral health status and its score could be used to evaluate priority for emergencies in this age group. Health policy implementations could be regulated in the frame of priorities related to preventive oral healthcare services.

Dental plaque biofilm cannot be eliminated. However, the pathogenic nature of the dental plaque biofilm can be reduced by reducing the bio-burden. ${ }^{42}$

\section{REFERENCES}

1. World Health Organization. Oral health surveys: basic methods. Geneva: World Health Organization; 2013.

2. Petersen PE, Bourgeois D, Ogawa H, Estupinan-Day S, NdiayeC. The global burden of oral diseases and risks to oral health. Bull World Health Organ 2005 Sep;83(9):661-669. 
3. Rowan-Legg A, Committee CP. Oral health care for childrena call for action. Paediatr Child Health 2013 Jan;18(1):37.

4. Feitosa S, Colares V, Pinkham J. The psychosocial effects of severe caries in 4-year-old children in Recife, Pernambuco, Brazil. Cad Saúde Pública 2005 Sep-Oct;21(5):1550-1556.

5. Mumcu G, Sur H, Yildirim C, Soylemez D, Atli H, Hayran O. Utilisation of dental services in Turkey: a cross-sectional survey. Int Dent J 2004 Apr;54(2):90-96.

6. Subasi F, Mumcu G, Koksal L, Cimilli H, Bitlis D. Factors affecting oral health habits among children with cerebral palsy: pilot study. Pediatr Int 2007 Dec;49(6):853-857.

7. Talekar BS, Rozier RG, Slade GD, Ennett ST. Parental perceptions of their preschool-aged children's oral health. J Am Dent Assoc 2005 Mar;136(3):364-372; quiz 81.

8. Medina-Solis CE, Maupome G, del Socorro Herrera M, PérezNúñez R, Ávila-Burgos L, Lamadrid-Figueroa H. Dental health services utilization and associated factors in children 6 to 12 years old in a low-income country. J Public Health Dent 2008 Winter;68(1):39-45.

9. Macrhy RV, Tuchtenhagen S, Agostini BA, da Silva Teixeira CR, Piovesan C, Mendes FM, Ardenghi TM. Socioeconomic and psychosocial predictors of dental healthcare use among Brazilian preschool children. BMC Oral Health 2013 Oct 31;13(1):60.

10. Goursand D, Paivai SM, Zarzar PM, Pordeus IA, Grochowski $\mathrm{R}$, Allison PJ. Measuring parental-caregiver perceptions of child oral health-related quality of life. Braz Dental J 2009;20(2):169-174.

11. Von Rueden U, Gosch A, Rajmil L, Bisegger C, RavensSieberer U. Socioeconomic determinants of health related quality of life in childhood and adolescence: results from a European study. J Epidemiol Community Health 2006 Feb;60(2):130-135.

12. Medina-Solís CE, Maupomé G, Ávila-Burgos L, Hijar-Medina M, Segovia-Villanueva A, Pérez-Núñez R. Factors influencing the use of dental health services by preschool children in Mexico. Pediatr Dent 2006 May-Jun;28(3):285-292.

13. Filstrup SL, Briskie D, Da Fonseca M, Lawrence L, Wandera A, Inglehart M. Early childhood caries and quality of life: child and parent perspectives. Pediatr Dent 2003 SepOct;25(5):431-440.

14. Pahel BT, Rozier RG, Slade GD. Parental perceptions of children's oral health: the Early Childhood Oral Health Impact Scale (ECOHIS). Health Qual Life Outcomes 2007 Jan 30;5(1):6.

15. Syrjälä A-MH, Knuuttila MLE, Syrjälä LK. Self-efficacy perceptions in oral health behavior. Acta Odontol Scand 2001 Feb;59(1):1-6.

16. Martins-Júnior PA, Ramos-Jorge J, Paiva SM, Marques LS, Ramos-Jorge ML. Validations of the Brazilian version of the Early Childhood Oral Health Impact Scale. Cad Saúde Pública 2012 Feb;28(2):367-374.

17. Lee GH, McGrath C, Yiu CK, King NM. Translation and validation of a Chinese language version of the Early Childhood Oral Health Impact Scale. Int J Paediatr Dent 2009 Nov;19(6):399-405.

18. Li S, Veronneau J, Allison PJ. Validation of a French language version of the Early Childhood Oral Health Impact Scale. Health Qual Life Outcomes 2008 Jan 22;6(1):9.

19. Jabarifar S-E, Golkari A, IJadi MH, Jafarzadeh M, Khadem P. Validation of a Farsi version of the early childhood oral health impact scale. BMC Oral Health 2010 Apr 6;10(1):4.
20. Nazdrajić AH. Translation and validation of the instrument for the oral health-related quality of life assessment in 3 to 5 years old children in Bosnia-Herzegovina. J Health Sci 2012;2(3):201-206.

21. Li S, Malkinson S, Veronneau J, Allison P. Testing responsiveness to change for the early childhood oral health impact scale. Community Dent Oral Epidemiol 2008 Dec;36(6):542-548.

22. Pani SC, Badea L, Mirza S, Elbaage N. Differences in perceptions of early childhood oral health-related quality of life between fathers and mothers in Saudi Arabia. Int J Paediatr Dent 2012 Jul;22(4):244-249.

23. Abanto J, Carvalho TS, Mendes FM, Wanderley MT, Bönecker M, Raggio DP. Impact of oral diseases and disorders on oral health-related quality of life of preschool children. Commun Dent Oral Epidemiol 2011 Apr;39(2):105-114.

24. Martins-Júnior P, Vieira-Andrade R, Corrêa-Faria $P$, Oliveira-Ferreira F, Marques L, Ramos-Jorge M. Impact of early childhood caries on the oral health-related quality of life of preschool children and their parents. Caries Res 2013;47(3):211-218.

25. Kramer PF, Feldens CA, Helena Ferreira S, Bervian J, Rodrigues PH, Peres MA. Exploring the impact of oral diseases and disorders on quality of life of preschool children. Commun Dent Oral Epidemiol 2013 Aug;41(4):327-335.

26. Scarpelli AC, Paiva SM, Viegas CM, Carvalho AC, Ferreira FM, Pordeus IA. Oral health-related quality of life among Brazilian preschool children. Community Dent Oral Epidemiol 2013 Aug;41(4):336-344.

27. Patel RR, Tootla R, Inglehart MR. Does oral health affect self perceptions, parental ratings and video-based assessments of children's smiles? Community Dent Oral Epidemiol 2007 Feb;35(1):44-52.

28. De Oliveira CM, Sheiham A. The relationship between normative orthodontic treatment need and oral healthrelated quality of life. Community Dent Oral Epidemiol 2003 Dec;31(6):426-436.

29. Rajab L, Petersen P, Bakaeen G, Hamdan M. Oral health behaviour of schoolchildren and parents in Jordan. Int J Paediatr Dent 2002 May;12(3):168-176.

30. Gökalp S, Doğan BG, Tekçiçek M, Berberoğlu A, Unlüer S. National survey of oral health status of children and adults in Turkey. Community Dent Health 2010 Mar;27(1):12-17.

31. Yusuf H, Gherunpong S, Sheiham A, Tsakos G. Validation of an English version of the Child-OIDP index, an oral healthrelated quality of life measure for children. Health Qual Life Outcomes 2006Jul 1;4(1):38.

32. Mumcu G, Inanc N, Ergun T, Ikiz K, Gunes M, Islek U, Yavuz S, Sur H, Atalay T, Direskeneli H. Oral health related quality of life is affected by disease activity in Behçet's disease. Oral Dis 2006 Mar;12(2):145-151.

33. Oliveira BH, Nadanovsky P. Psychometric properties of the Brazilian version of the Oral Health Impact Profile-short form. Community Dent Oral Epidemiol 2005 Aug;33(4):307-314.

34. Scarpelli AC, Oliveira BH, Tesch FC, Leão AT, Pordeus IA, Paiva SM. Psychometric properties of the Brazilian version of the Early Childhood Oral Health Impact Scale. BMC Oral Health 2011;11(1):19.

35. Barbosa T, Gavião M. Oral health-related quality of life in children: Part III. Is there agreement between parents in rating their children's oral health-related quality of life? A systematic review. Int J Dent Hygiene 2008 May;6(2):108-113. 
36. Savage MF, Lee JY, Kotch JB, Vann WF. Early preventive dental visits: effects on subsequent utilization and costs. Pediatrics 2004 Oct;114(4):e418-e423.

37. Ganavadiya R, Chandrashekar B, Goel P, Hongal S, Jain M. Mobile and portable dental services catering to the basic oral health needs of the underserved population in developing countries: a proposed model. Ann Med Health Sci Res 2014 May;4(3):293-304.

38. Jürgensen N, Petersen P. Promoting oral health of children through schools-results from a WHO global survey 2012 Community Dent Health 2013 Dec;30(4):204-218.
39. Slade GD, editor. Measuring oral health and quality of life. Background and Rationale for the Conference; 1997.

40. Mumcu GKL, Şişman N. An analysis of oral health campaigns from a social marketing perspective. Galatasaray Üniversitesi ileti-ş-im Dergisi 2013;3:53-72.

41. Watt RG. Strategies and approaches in oral disease prevention and health promotion. Bull World Health Organ 2005 Sep;83(9):711-718.

42. Saini RA Prospective Experimental Comparative Study on the Clinical Effects of Calculus Dissolution based Oral Rinse in Gingivitis Patients. Int J Experiment Dent Sci 2015;4(1):33-39. 